\title{
Calculating the Incalculable: Is SAI the Lesser of Two Evils?*
} Mike Hulme

The possibility of altering the world's climate through intentional stratospheric aerosol injection $(\mathrm{SAI}$ — or indeed through any other solar radiation management (SRM) technology—brings with it not just a new technology for humans to consider but a new category of problem. As authors such as Bron Szerszynski, Willis Jenkins, and Christopher J. Preston have pointed out, intervening deliberately in the skies would "begin the era of global artificing." In his article “Carbon Emissions, Stratospheric Aerosol Injection, and Unintended Harms," which explores the relative moral culpability of agents inducing climate harms through their actions, Preston applies the doctrine of double effect (DDE) to investigate one specific question: Does intentionality make an ethical difference when considering culpability for causing climate harms? He reaches the conclusion—surprising both to him and to me — that those who might deliberately engineer the world's climate through SAI may be less culpable than those who continue to emit greenhouse gases (GHGs). In his application of the DDE, Preston offers four conditions that need to be fulfilled in order for the doctrine to be able to shield an agent from some portion of culpability: (a) the intended final end must be good; (b) the intended means must be morally acceptable; (c) the foreseen bad upshot must not itself be willed; and (d) the good end must be proportionate to the bad upshot (p. XXX). Preston argues that conditions (a), (c), and (d) are fulfilled by a hypothetical benevolent climate engineer, but concedes that some might argue

\footnotetext{
* This essay is in response to Christopher J. Preston's "Carbon Emissions, Stratospheric Aerosol Injection, and Unintended Harms," Ethics \& International Affairs 31, no. 4 (2017).
} 
that condition (b) is not. This concession is a gesture to those commentators - such as Dale Jamieson and Clive Hamilton-who argue on moral grounds that intentional climate engineering is not something that humans should do because it is inherently wrong (a position that Preston himself on occasions seems to have argued). ${ }^{2}$

Preston's exploration of the application of the DDE as a partial ethical defense for SAI is provocative and useful, but it leads to a confusing and unpersuasive conclusion. My concerns are focused not on condition (b) but rather on conditions (a), (c), and (d). ${ }^{3}$ Specifically, there are three (related) aspects of his argument that leave me unconvinced: the implied symmetry between SAI and GHG-induced climate goods and harms, the (potential) knowability of the harms, and the surprising absence in his discussion of the political implications of SAI.

\section{ASYMmetry}

I think Preston underplays the asymmetry between the public goods potentially provided by SAI and those provided by GHG emissions. The sole purpose behind GHG emissions is, and always has been, to provide cheap and reliable energy to enable the provision of welfare goods. ${ }^{4}$ There is no intention from the emitters of GHGs to cause harm, even though it has now emerged that their emissions have resulted in substantial harm. As Preston himself says, "anthropogenic climate change remains an accident of atmospheric chemistry" (p. XXX).

The sole purpose of SAI, however, is to undo some of the unintended harms of GHG emissions. Yet the ethical cost of limiting some of these harms is inevitably to introduce other climate harms of an indeterminate nature. Unlike the purveyors of coal in nineteenth-century Britain, the putative SAI engineers have their eyes wide open. There is no other public good 
delivered by SAI; it is merely in the business of harm limitation through trying to reverse engineer the climate system. I do not think it is therefore entirely fair to treat these two actions symmetrically as Preston does. The "good ends" of SAI and GHG are quite different, which makes them much harder to equate using a quantified cost-benefit analysis. The benefits of GHG emissions are expressed in terms of energy-related welfare goods, whereas the benefits of SAI are expressed as the negative costs of avoided climate harms.

At the very least this asymmetry makes the type of cost-benefit calculation on which Preston's argument relies considerably more challenging. It also lends weight to the "closeness" criticism of the DDE offered by Preston and originating from Philippa Foot. ${ }^{5}$ In the case of SAI, the benefits and costs are all related to future climate harms - the benefits being harms avoided, and the costs being new harms introduced. Preston's case relies on being able to distinguish between these harms, a forensic task likely to be well beyond the capability of analysts. By contrast, in the case of GHG emissions the benefits are welfare goods generated through energy services - goods of a quite different nature from the harms introduced inadvertently by changing the climate.

\section{INDETERMINACY}

Central to Preston's argument is the (assumed) knowability of the harms that result from SAI and from GHG and (importantly) the ability of some knowledgeable agent to be able to distinguish between them. However, Preston is guilty of circular reasoning here. He assumes that the climate engineer has "overwhelming evidence that the benefits of deployment will outweigh the harms" 
(p. XXX), and he uses this very same assumption to satisfy criterion (d) in the DDE defense of SAI.

In defense of his position, Preston argues that the harms of GHG emissions (by which he means some cost-benefit calculation of the consequences of using fossil fuels) are more certain than those of SAI. But there are three problems here. First, if we concede (correctly in my view) that the harms of SAI are poorly known (or at least less well-known than those resulting from GHGs), ${ }^{6}$ we cannot therefore safely assume that they are lesser than those resulting from GHGs. Calculating the harms of SAI requires knowing the original harms caused by GHGs (which are of course to be limited) and also the additional harms introduced by SAI, a double calculation of uncertain risks.

Second, it is dubious whether the harms of GHG emissions are actually as well-known or calculable as Preston implies, let alone those of SAI. We know that GHG emissions cause changes in the climate, and that these changes have tangible and potentially harmful effects. Preston lists some of these qualitatively. But this is not the same as calculating future harms in quantified and hence comparative form. Preston seems supremely confident that climate harms can be established "satisfactorily" through "extensive modeling" (p. XXX), but as others have argued, efforts to determine an ethically credible and epistemically robust social cost of carbon are doomed to failure. ${ }^{7}$ Given that the resolution of this question is "the sine qua non of any credible argument for climate engineering" (p. XXX), it is not promising that Preston has to "assume that the climate engineer has overwhelming evidence" (p. XXX) that the benefits of SAI deployment outweigh the costs.

The third problem with Preston's position on harms concerns their distributional effects. The full import of the harms of SAI (or of GHG emissions) is not in their aggregate effect, 
gauged against the global temperature index. While the justification of SAI is usually expressed in terms of containing the rise in global temperature, its effects on regional climate and weather patterns will be quite different. Deploying SAI to stabilize the global temperature or limit its warming to 1.5 degrees Celsius is not simply a case of reverse engineering the climate system back to some prior predictable state. Regional climates and local weather respond in nonlinear ways to different external forces, such that "undoing" the harms caused by GHGs cannot be guaranteed just by resetting the global temperature. Rather, the climate harms from SAI will be a function of the timing, reliability, and geography of the SAI deployment, factors that will lead to very different regional climate responses. ${ }^{8}$ In other words, the harms of SAI are first and foremost to be determined distributionally and the uncertainties of these distributional effects (not least in relation to precipitation dynamics) are considerably greater than those associated with globally aggregated harms. It matters not just that there may only be a "small minority" of people adversely affected by SAI (p. XXX) or "some [undetermined] unlucky populations" (p. $\mathrm{XXX})$, but crucially which minority and which populations become the unlucky victims.

\section{Politics}

Because the harms associated with SAI are first and foremost distributional in nature, the act of climate engineering through SAI carries huge political implications. Beyond agreeing with David Keith that SAI might "shake up the stale politics of climate change," Preston-implying without further explanation that this would be a good thing — sidesteps the political problem of SAI by assuming that it would only be undertaken once a "broad consensus" has been reached about the "overall" favorable cost-benefit ratio of the climate effects of SAI (p. XXX). This again hints of 
circular reasoning and avoids political realities. Again, the politics of SAI are not about an "overall” (globally aggregated) comparison of harms, but very specifically about how these respective harms are regionally differentiated and credibly attributed to different types of actions. This might very well shake up the politics, but in a deeply unconstructive manner. Preston talks about the need to reduce the social and ethical doubts of climate engineering through SAI, but makes no mention of the need to reduce the political ramifications.

My point here is that in establishing the harms of SAI one should not simply be weighing the relevant climate-induced harms (aggregated or distributed) against those resulting from GHG emissions. Rather, one should also consider the additional "political harms" that would flow from any implementation of an SAI climate engineering strategy. I have explored some of these harms elsewhere, ${ }^{9}$ and they are considerable, as they layer further political complexity over the already troubled politics and justice implications of negotiating conventional GHG mitigation. For example, SAI opens up the possibility of new interstate actions under international law for harms caused, and also introduces the possibilities of nonstate SAI engineers operating beyond national or international jurisdictions. The force of Preston's overall argument, which challenges one of the ethical reasons not to engineer the climate through SAI, seems considerably weakened by not including any of these political considerations.

\section{CONCLUSION}

Preston is correct to suggest that his argument is unwelcome for "people who view climate engineering as unacceptable from any angle" (p. XXX). Although not arguing against SAI on moral or ontological grounds, I have argued against it using epistemic, environmental, and 
political criteria. ${ }^{10}$ And although Preston concludes that GHG mitigation remains the ultimate moral priority, paradoxically he has developed an argument which, he claims, diffuses one ethical objection for those who are seeking to promote SAI as a viable climate management strategy. Preston's ethical pass for SAI engineers is not well-grounded for the reasons explained above: centrally, that his argument is based on the utilitarian paradigm of comparative costbenefit analysis, which I do not believe can offer the sure foundation for ethical reasoning he seems to suggest it does.

Preston's argument could be read as suggesting that "two wrongs make a right" or that SAI is the "lesser of two evils." Yet even if one buys into Preston's use of DDE to defend such reasoning, SAI might still be sensibly resisted as being unfeasible, unjust, or simply unwise.

\section{NOTES}

${ }^{1}$ Christopher J. Preston, "Beyond the End of Nature: SRM and Two Tales of Artificity for the Anthropocene," Ethics, Policy \& Environment 15, no. 2 (2012), p. 191.

${ }^{2}$ See, for example, Christopher J. Preston, "Re-Thinking the Unthinkable: Environmental Ethics and the Presumptive Argument against Geoengineering," Environmental Values 20, no. 4 (2011), pp. 457-79.

${ }^{3}$ For my position regarding condition (b), see Mike Hulme, Can Science Fix Climate Change? A Case Against Climate Engineering (Cambridge, U.K.: Polity Press, 2014).

${ }^{4}$ For the sake of the argument here, I focus only on GHG emissions resulting from energy generation and ignore emissions related to land use, although the latter are also a by-product of securing necessary welfare goods.

${ }^{5}$ See Philippa Foot, Virtues and Vices and Other Essays in Moral Philosophy (Berkeley, Calif.: University of California Press, 1978).

${ }^{6}$ Preston is somewhat inconsistent here. On p. XXX he states that the overall reduction in harms caused by the use of SAI is not known (and can only be established through extensive modeling), yet on p. XXX he states that the harms of SAI are known.

${ }^{7}$ See, for example, John C. V. Pezzey and Paul J. Burke, "Towards a More Inclusive and Precautionary Indicator of Global Sustainability," Ecological Economics 106 (2014), pp. 14154.

${ }^{8}$ For a recent demonstration of this, see Aditya Nalam, Govindasamy Bala, and Angshuman Modak, "Effects of Arctic Geoengineering on Precipitation in the Tropical Monsoon Regions," Climate Dynamics (2017, early view), pp. 1-21, doi:10.1007/s00382-017-3810-y. 
${ }^{9}$ Mike Hulme, Can Science Fix Climate Change?

${ }^{10}$ Ibid.

\begin{abstract}
Christopher J. Preston's use of the doctrine of double effect to claim that hypothetical climate engineers might very well be less culpable for climate harms than those who continue to emit greenhouse gases is unpersuasive. His argument rests shakily on the ability to determine and quantify climate harms and to distinguish forensically between their causes. He is also largely silent about the distributional effects of these harms and their ethical and political ramifications.
\end{abstract}

Keywords: climate engineering; stratospheric aerosol injection; doctrine of double effect; unintended harms; distributional climate impacts 